\title{
Targeting of surface alpha-enolase inhibits the invasiveness of pancreatic cancer cells
}

\author{
Moitza Principe ${ }^{1,2, *}$, Patrizia Ceruti ${ }^{1,2, *}$, Neng-Yao Shih ${ }^{3, *}$, Michelle S. Chattaragada ${ }^{1,2}$, \\ Simona Rolla ${ }^{1,2}$, Laura Conti ${ }^{2,4}$, Marco Bestagno ${ }^{5}$, Lorena Zentilin ${ }^{5}$, Sheng-Hui \\ Yang ${ }^{6}$, Paola Migliorini ${ }^{7}$, Paola Cappello ${ }^{1,2}$, Oscar Burrone ${ }^{5}$ and Francesco Novelli ${ }^{1,2}$ \\ ${ }^{1}$ Center for Experimental Research and Medical Studies (CeRMS), Azienda Universitaria Ospedaliera Città della Salute e della \\ Scienza di Torino, Turin, Italy \\ 2 Department of Molecular Biotechnology and Health Sciences, University of Turin, Turin, Italy \\ ${ }^{3}$ National Institute of Cancer Research, National Health Research Institutes, Tainan City, Taiwan \\ ${ }^{4}$ Molecular Biotechnology Center (MBC), University of Turin, Turin, Italy \\ ${ }^{5}$ International Centre for Genetic Engineering and Biotechnology (ICGEB), Trieste, Italy \\ ${ }^{6}$ College of Medical Science and Technology, Taipei Medical University, Taipei City, Taiwan \\ 7 Department of Clinical and Experimental Medicine, University of Pisa, Italy \\ * These authors contributed equally to this work \\ Correspondence to: Francesco Novelli, email: franco.novelli@unito.it
}

Keywords: pancreatic cancer, ENO1, plasminogen, monoclonal antibody, adeno-associated virus

Received: February 05, $2015 \quad$ Accepted: February 22, $2015 \quad$ Published: March 14, 2015

This is an open-access article distributed under the terms of the Creative Commons Attribution License, which permits unrestricted use, distribution, and reproduction in any medium, provided the original author and source are credited.

\section{ABSTRACT}

Pancreatic Ductal Adenocarcinoma (PDAC) is a highly aggressive malignancy characterized by rapid progression, invasiveness and resistance to treatment. We have previously demonstrated that most PDAC patients have circulating antibodies against the glycolytic enzyme alpha-enolase (ENO1), which correlates with a better response to therapy and survival. ENO1 is a metabolic enzyme, also expressed on the cell surface where it acts as a plasminogen receptor. ENO1 play a crucial role in cell invasion and metastasis by promoting plasminogen activation into plasmin, a serine-protease involved in extracellular matrix degradation. The aim of this study was to investigate the role of ENO1 in PDAC cell invasion. We observed that ENO1 was expressed on the cell surface of most PDAC cell lines. Mouse anti-human ENO1 monoclonal antibodies inhibited plasminogen-dependent invasion of human PDAC cells, and their metastatic spreading in immunosuppressed mice was inhibited. Notably, a single administration of Adeno-Associated Virus (AAV)-expressing CDNA coding for 72/1 anti-ENO1 mAb reduced the number of lung metastases in immunosuppressed mice injected with PDAC cells. Overall, these data indicate that ENO1 is involved in PDAC cell invasion, and that administration of an anti-ENO1 mAb can be exploited as a novel therapeutic option to increase the survival of metastatic PDAC patients.

\section{INTRODUCTION}

Pancreatic Ductal Adenocarcinoma (PDAC) is the fourth leading cause of cancer mortality in developed countries. Despite the available treatment, PDAC has the worst prognosis of all major malignancies, with a 5 -year survival rate of $6 \%$ and a median survival of 6 months after diagnosis $[1,2]$. The high mortality rate associated with PDAC is almost equal to the incidence rate, and is caused by the high frequency of metastatic disease found at diagnosis $[3,4]$.

The plasminogen system is involved in tumor growth, invasion and metastasis [5-7]. Urokinase (uPA) and tissue (tPA) plasminogen activators released from cancer cells catalyze the proteolytic conversion of plasminogen to plasmin, leading to degradation of the 
extracellular matrix (ECM), thus facilitating cancer cell invasion [5-8]. The uPA receptor (UPAR) is a cell membrane-anchored protein which aids the accumulation of plasminogen at the cell surface [5]. Binding proteins for plasminogen include alpha-Enolase (ENO1), Annexin 2 (ANX2) and Cytokeratin 8 (CK8) [9]. Among these, ENO1 has been classified as a pancreatic cancer-associated antigen as it is overexpressed in PDAC and induces both humoral and $\mathrm{T}$ cell-specific responses in patients $[10,11]$.

In this study, a multiple approach was adopted to investigate the role of ENO1 in the invasion and metastasis of PDAC, and to develop possible therapeutic options, based on ENO1 regulation, aimed to counteracting the invasiveness of this tumor. We evaluated i) the expression of ENO1, UPA and UPAR and of plasminogen-induced migration, in a panel of eight PDAC cell lines; ii) the in vitro and in vivo effects of anti-ENO1 monoclonal antibodies (mAbs); iii) the in vitro and in vivo effects of ENO1 silencing or mutations of its plasminogen-binding site, and iv) the effect of administering recombinant adeno-associated viral vector (AAVV) for the expression of complete anti-ENO1 mAb in in vivo metastatization.

\section{RESULTS}

\section{Analysis of ENO1, uPAR and uPA expression in PDAC cell lines}

Flow-cytometry, using specific $72 / 1 \mathrm{mAb}$, revealed that ENO1 was expressed on the surface of the majority of the tumor cell lines tested, namely PT45, MIA PaCa2, Hs766T, T3M4, CFPAC-1, and L3.6pl. High ENO1 expression was found in T3M4, CFPAC-1 and L3.6pl, cells; there was intermediate ENO1 expression in MIA PaCa-2, Hs766T, and PT45 cells, and low or no ENO1 expression in BxPC-3 and PANC-1 cells (Fig. 1a upper panel). By contrast, all cell lines expressed similar levels of total ENO1 (Fig. 1a lower panel).

In addition to plasminogen receptors, such as ENO1, plasminogen activation requires the plasminogen activation system, as such, uPA and UPAR expression in PDAC cell lines was evaluated. After flow-cytometry analysis, we observed high levels of uPAR in PT45 and CFPAC-1 cells, intermediate levels in BxPC-3, PANC-1, MIA PaCa-2, and Hs766T cells, and low or zero levels in T3M4 and L3.6pl cells (Fig. 1b). uPA expression was high in BxPC-3, PANC-1 and CFPAC-1 cells, intermediate in PT45, and T3M4 cells, and low or absent in MIA PaCa-2, Hs766T and L3.6pl cells (Fig. 1c).

\section{Effect of the blockade of ENO1 on plasminogen- dependent invasion of PDAC cells}

In the presence of plasminogen, CFPAC-1 cells were strongly invasive compared to those in the absence of plasminogen (Fig. S1a and b). No increase in invasion was observed in the presence of plasminogen for any of the other cell lines (Fig. S1a, b). As the CFPAC-1 cells produced uPA and expressed both surface UPAR and ENO1, they were able to invade in response to plasminogen. Nevertheless, as TGF- $\beta$ has been shown to up-regulate both uPA and uPAR [12], its effect on plasminogen-dependent invasion was evaluated. In ENO1 expressing T3M4 and in L3.6pl cells, TGF- $\beta$ increased the expression of uPAR and uPA (Fig. S1c) and rendered them responsive to plasminogen-dependent invasion (Fig. S1d and Table S1).

In the presence of anti-ENO1 mAb, the plasminogen-dependent invasiveness of both CFPAC-1 (Fig. 2a) and TGF- $\beta$-treated-T3M4 (Fig. 2b) cells was significantly reduced. The extent of this reduction was similar to that induced in CFPAC-1 cells by the plasminogen system inhibitor EACA (Fig. 2a). By contrast, BxPC-3 cells, which expressed very low levels of ENO1, did not invade in the presence of plasminogen, and were not affected by the addition of anti-ENO1 mAb (Fig. 2a lower panel). These results were also confirmed using the Oris ${ }^{\mathrm{TM}}$-FLEX Platypus Kit, in which cells were completely plunged into Matrigel and their invasion was evaluated in the absence of chemotactic stimuli, by measuring their ability to fill a central hole in the well (Fig. 2c).

In the presence of plasminogen, a similar growth pattern was observed when PDAC cells were cultured with anti-ENO1 mAb or isotype-control Ab (Fig. S2). This ruled out the possibility that the inhibitory effect of the anti-ENO1 $\mathrm{mAb}$ on migration is due to interference with the growth of tumor cells.

\section{Effect of mutation of ENO1 plasminogen binding sites on the plasminogen-dependent invasion of PDAC cells}

ENO1 expression was silenced in CFPAC-1 cells with a lentivirus delivering an shRNA targeting ENO1 or the 3'UTR (shENO1). A scrambled shRNA (shCTRL) was used as a control. Both ENO1 mRNA (Fig. S3a upper panel) and protein levels (Fig. S3a lower panel), as well as plasminogen-induced invasion (Fig. S3b) were efficiently reduced after silencing in CFPAC-1 shENO1 cells. Infection of CFPAC-1 cells with a second shRNA targeting the ENO1 CDS region (shENO1\#2) gave similar results (Fig. S3). All subsequent experiments were carried out using CFPAC-1 shENO1 cells.

FACS analysis revealed that $\mathrm{UPA}$ and $\mathrm{UPAR}$ 
a
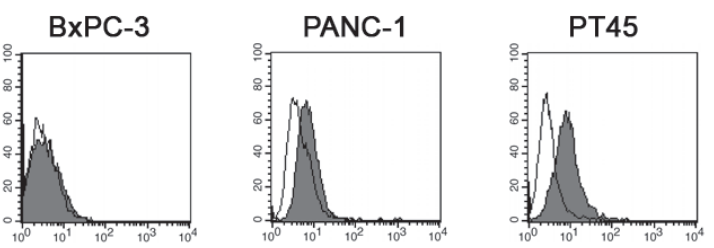

MIA PaCa-2

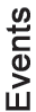
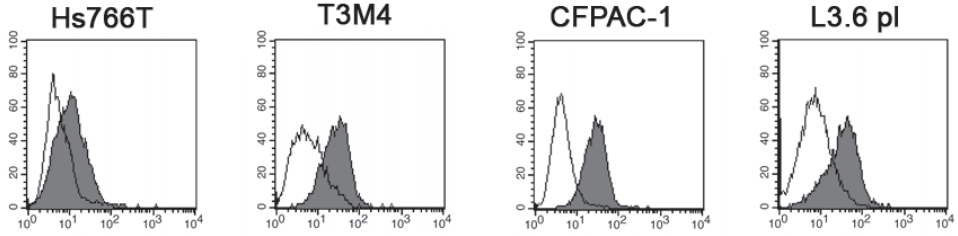

ENO1
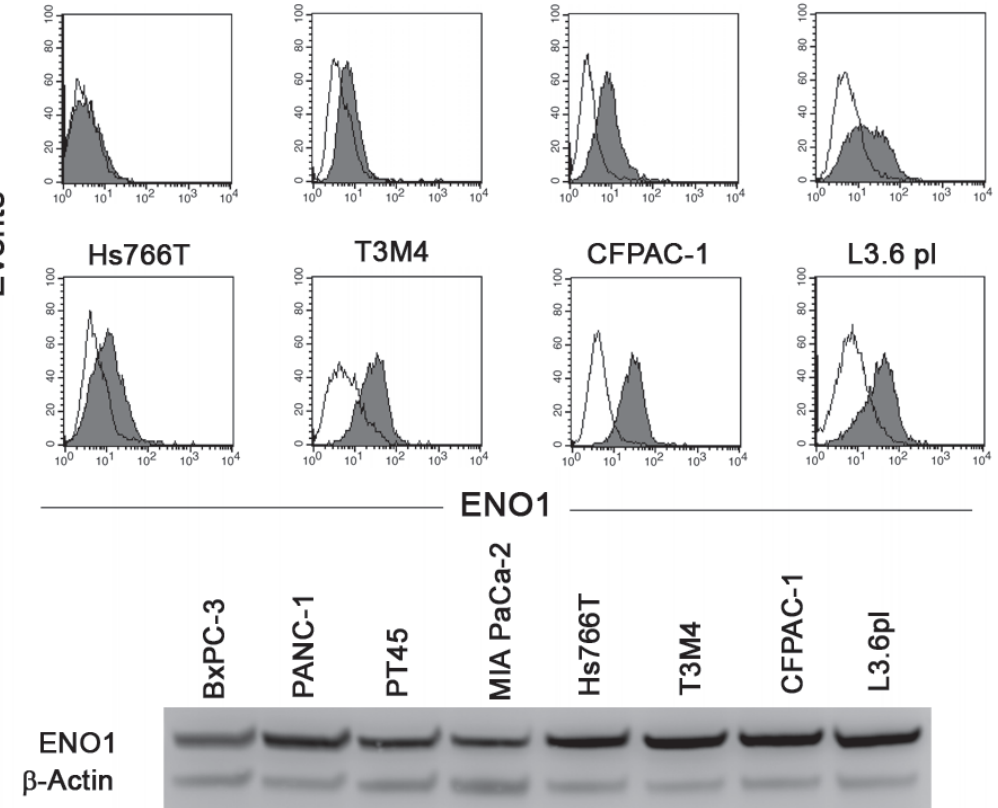

b

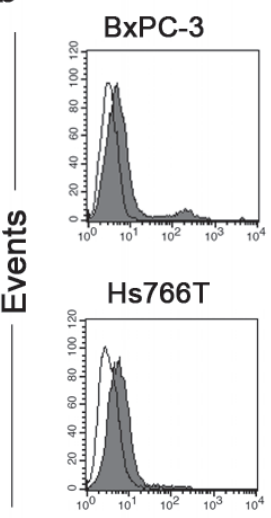

PANC-1

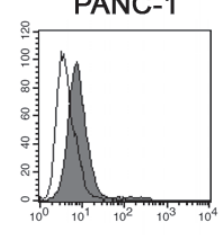

PT45

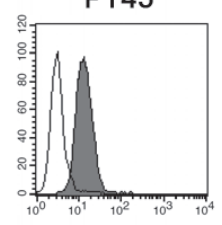

MIA PaCa-2

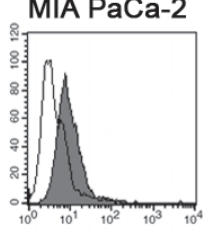

T3M4
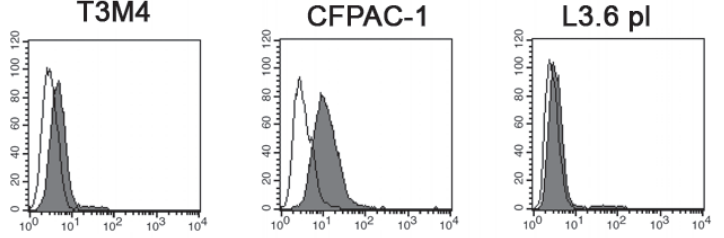

UPAR

C
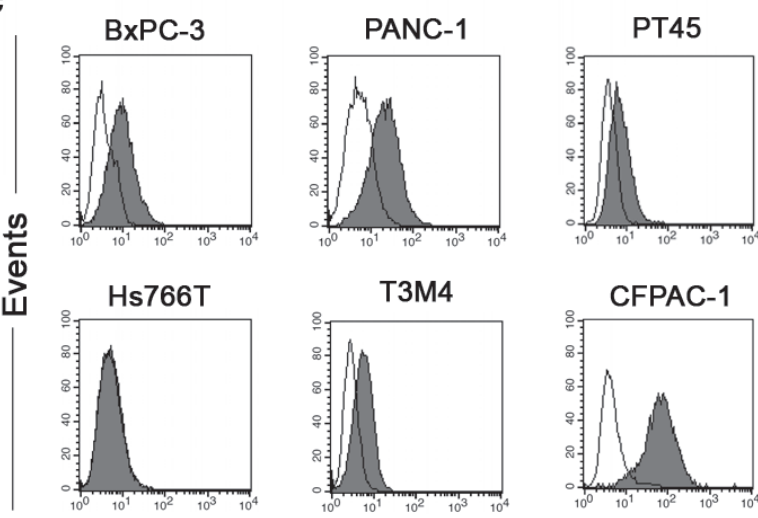

MIA PaCa-2

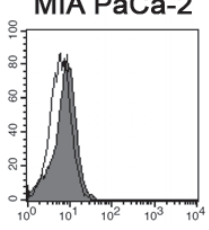

T3M4
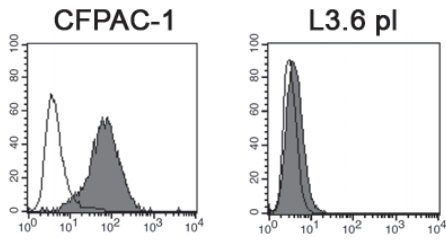

uPA

Figure 1: Analysis of ENO1, uPAR and uPA expression in PDAC cell lines. PDAC cell lines were incubated with anti-ENO1 $72 / 1 \mathrm{mAb}$ (solid histogram a), anti-uPAR antibody (solid histogram b), anti-uPA (solid histogram c) or an isotype-matched control antibody (open histogram) and analyzed by flow-cytometry. To evaluate intracellular expression of ENO1 (a, lower panel), Western blot analysis was performed on whole cell lysates of all PDAC cell lines with anti-ENO1 72/1 mAb. Results were normalized using $\beta$-Actin. A representative of three independent experiments is shown. 
expression was not modified by ENO1 silencing in CFPAC-1 cells (Fig. S3c).

To assess the contribution of ENO1 to PDAC invasion, shENO1 cells were transfected with a mutated form of ENO1 (shENO1+TM), in which three lysines of the plasminogen binding site at the C-terminal [13] were substituted with three arginines, resulting in a nonfunctional plasminogen binding site (Fig. 3a). shENO1 cells transfected with a wild type full-length exogenous ENO1 (shENO1+WT) or Empty vector (shENO1+Empty) were used as a controls. WB analysis showed that shENO1+WT or shENO1+TM rescued ENO1 protein levels (Fig. 3b upper panel). Flow cytometric analysis showed a lack of ENO1 surface expression in shENO1 and shENO1+Empty (Fig.3b lower panel and not shown) whereas ENO1 surface expression in shENO1+WT or shENO1+TM was rescued (Fig. 3b lower panel). These data demonstrated that the triple mutation in the plasminogen binding site resulted in the inability of ENO1 to bind plasminogen without its cell surface expression being affected.

Cells were then tested for invasive capacity in response to plasminogen. Control shENO1 CFPAC-1 cells failed to invade through the Matrigel, whereas shENO1+WT cells recovered this ability, but to a lesser extent compared to CFPAC-1 shCTRL cells (Fig. 3c). Notably, shENO1+TM cells significantly reduced invasion in response to plasminogen compared to the shENO1+WT cells (Fig. 3c). To confirm the contribution of ENO1 to in vivo invasion and metastasis, NSG immunocompromised mice were injected i.v. with shENO1+TM, shENO1+WT or shENO1+Empty CFPAC-1 cells. On day 28, postmortem observations confirmed a significantly reduced metastatic area in the lungs of mice injected with shENO1+Empty or with shENO1+TM cells versus mice injected with shENO1+WT CFPAC-1 cells (Fig. 3d). a

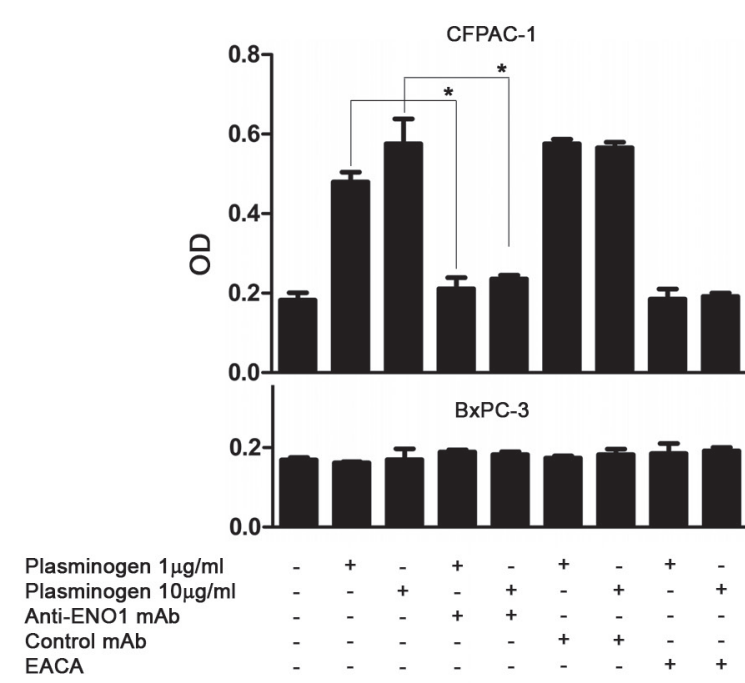

c
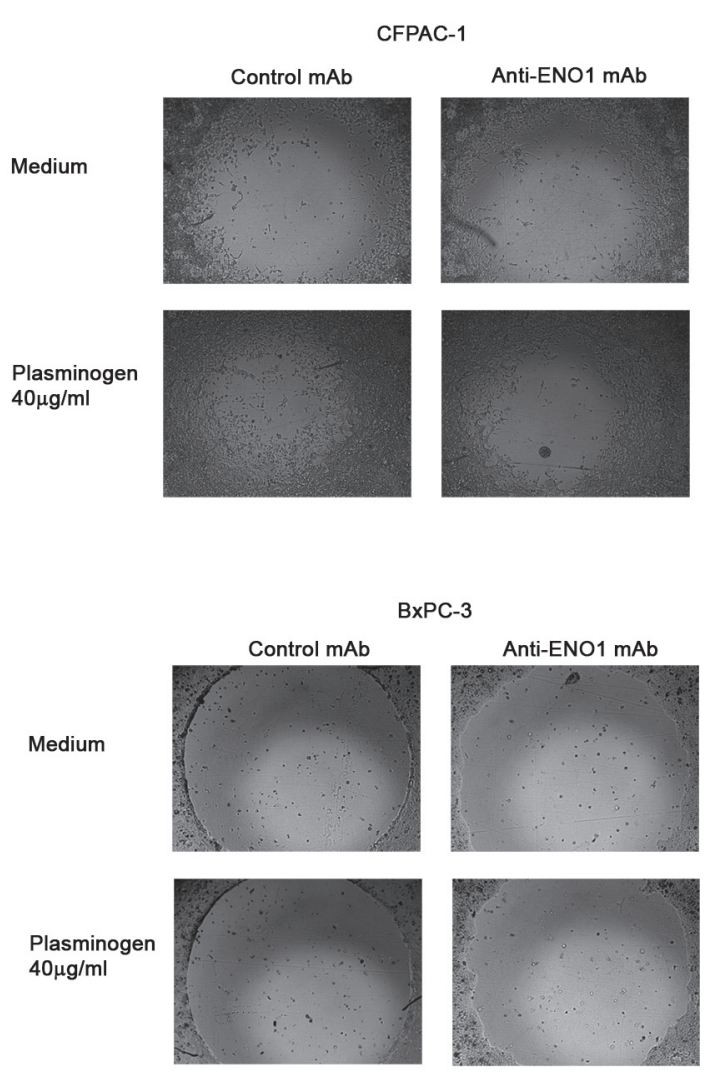

Figure 2: Anti-ENO1 72/1 mAb inhibits plasminogen-dependent invasion of PDAC cells. (a) CFPAC-1 (upper panel), BxPC3 (lower panel) and T3M4 (b) were placed on Matrigel-coated transwell filters and plasminogen ( $1 \mu \mathrm{g} / \mathrm{ml} \mathrm{or} 10 \mu \mathrm{g} / \mathrm{ml})$, anti-ENO1 mAb 72/1 $(50 \mu \mathrm{g} / \mathrm{ml})$ or an isotype-matched IgG1 mAb $(50 \mu \mathrm{g} / \mathrm{ml})$, EACA $(50 \mathrm{mM})$ and TGF- $\beta(10 \mathrm{ng} / \mathrm{ml})$ were added in appropriate conditions. Data are reported as mean \pm SEM of Optical Density units (OD) and the different conditions were repeated in triplicate. (c) Effect of anti-ENO1 $72 / 1 \mathrm{mAb}$ on migration in Matrigel (Oris ${ }^{\mathrm{TM}}$ Platipus kit) of CFPAC-1 (upper panel) and BxPC3 (lower panel) cultured in the presence of 50 $\mu \mathrm{g} / \mathrm{ml}$ of anti-ENO1 or IgG1 control mAb with or without plasminogen $(40 \mu \mathrm{g} / \mathrm{ml})$. Images are taken at x 5 magnification. A representative of three independent experiments is shown. ${ }^{*} \mathrm{p}<0.05 ; * * \mathrm{p}<0.01 ; * * * \mathrm{p}<0.001$ 


\section{Anti-ENO1 mAb blocks liver metastasis in an orthotopic pancreatic tumor model}

To better characterize the role of ENO1 in in vivo tumor spreading, PANC-1/P cells with low expression of surface ENO1 were orthotopically injected into pancreases of NOD-SCID mice. Metastatic cells were harvested from livers and cultured, and were designated as PANC-1/M. Western blot analysis of total ENO1 protein showed that its expression level in PANC-1/P cells was significantly up-regulated, compared to that in normal-like human pancreatic duct epithelial cells, HPDE (Fig. 4a left). Conversely, although the total amount of ENO1 was not increased in metastatic PANC-1/M cells, its surface distribution was clearly augmented in these cells (Fig. 4a right), confirming that surface ENO1 may play a crucial role in tumor metastasis.

To confirm the potential therapeutic use of an anti-ENO1 $\mathrm{Ab}$ for metastatic PDAC, experiments were conducted with a different anti-ENO1 mAb, namely E10A. The invasion of metastatic PANC-1/M cells treated with the anti-ENO1 mAb was significantly suppressed in a dose-dependent manner (Fig. 4b). In addition, these cells were orthotopically injected into the pancreases of NOD-SCID mice, followed by i.v. administration of the anti-ENO1 $\mathrm{mAb}$ or its isotype $\mathrm{mAb}$ at $2 \mathrm{~h}$ and $24 \mathrm{~h}$ postinoculation. Metastatic tumor cells were fluorescently tracked by the IVIS system, showing that, in the orthotopic model, the liver was the major target for tumor metastasis of PANC-1/M cells, although a few metastatic colonies were detected in lungs and spleens (Fig. 4c upper left). Although two control mice died at 2 weeks prior to the completion of the experiments, the number and tumor a

ENO WT 415 EELGSKAKFAGRNFRNPLAK 434

ENO TM 415 EELGSRARFAGRNFRNPLAR 434

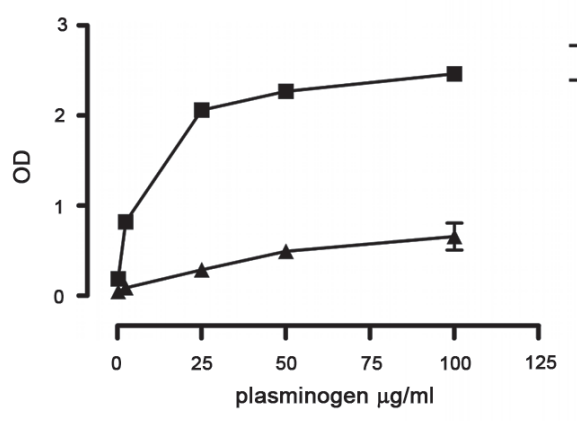

C

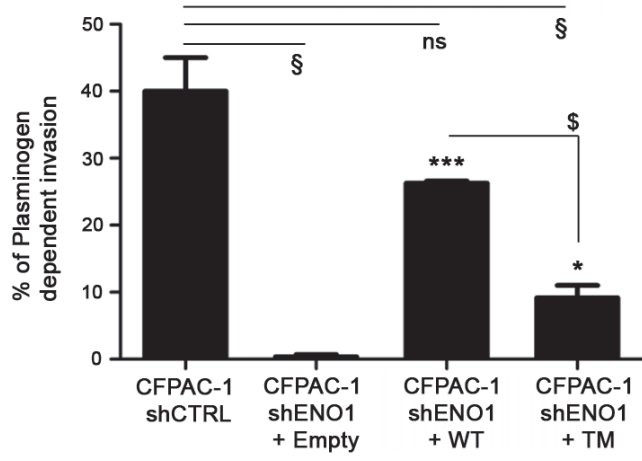

b

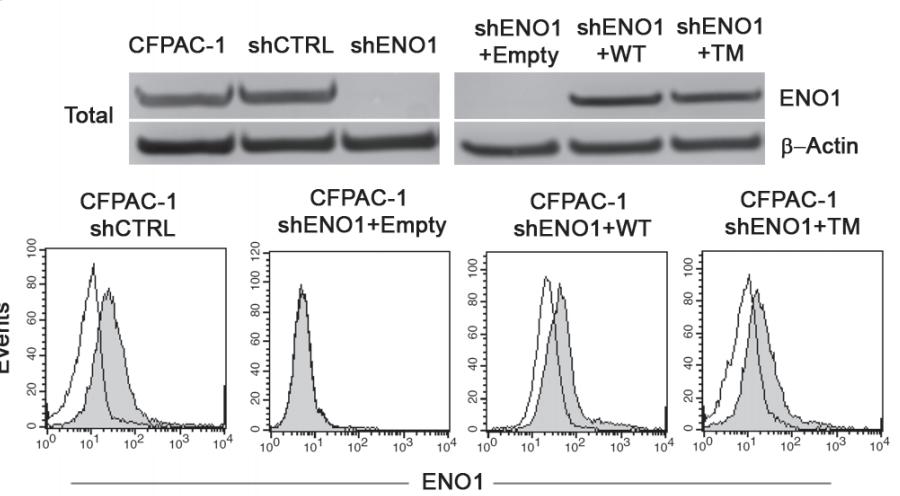

d

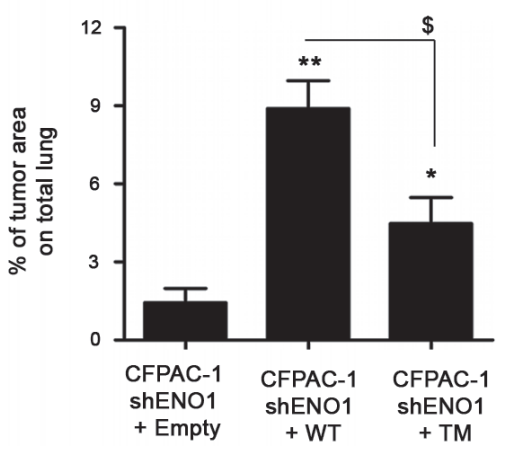

Figure 3: Plasminogen-dependent invasion of CFPAC-1 shENO1 transfected with WT, TM or Empty vector. (a) Upper panel, a schematic representation of plasminogen-binding sites on ENO1 bearing mutations on lysines 420, 422 and 434 is shown. Lower panel, plasminogen binding to recombinant ENO1 WT or rENO1 TM was evaluated by ELISA. Data are reported as mean \pm SEM of Optical Density units (OD) and the different conditions were repeated in triplicate. (b) CFPAC-1 shCTRL, CFPAC-1 shENO1+Empty, shENO1+WT, shENO1+TM cell lines were checked for the expression of ENO1 in the total cell lysates (b, upper panel). Results were normalized using $\beta$-Actin. For determining surface expression, cells were incubated with anti-ENO1 72/1 mAb (solid histogram) or an isotype-matched control antibody (open histogram) and analyzed by flow-cytometry (b, lower panel). (c) Invasion of CFPAC-1 shCTRL, shENO1+WT, shENO1+TM or shENO1+Empty cells in the presence or absence of $10 \mu \mathrm{g} / \mathrm{ml}$ plasminogen. Results represent the percentage of plasminogen-dependent invasion calculated as: (OD of migrated cells in the presence of plasminogen / OD of migrated cells in the absence of plasminogen) x100. (d) Growth of CFPAC-1 shENO1+WT, shENO1+TM and shENO1+Empty cells in the lungs of i.v. injected NSG mice. Bars represent the percentage of tumor area calculated as: (tumor area / total area) $\mathrm{x} 100$. Data are reported as mean \pm SEM of five mice per group. *p $<0.05 ; * * \mathrm{p}<0.01 ; * * \mathrm{p}<0.001$ Statistic analysis respect to CFPAC-1 shENO1+Empty $\left({ }^{*}\right)$, to CFPAC-1 shENO1+WT (\$) or to CFPAC-1 shCTRL (§). 
volume of visible metastatic colonies in livers of mice treated with the anti-ENO1mAb were markedly decreased compared to mice treated with the control mAb (Fig. 4c upper right). This observation was further confirmed by directly weighing each organ. Again, treatment with the anti-ENO1 mAb substantially reduced metastatic tumor masses in livers (Fig. 4c lower panel). The average weights of the livers of the anti-ENO1 mAb-treated mice were comparable to those of age-matched un-injected mice.

\section{Anti-ENO1 mAb reduces the in vivo growth and metastasis of CFPAC-1 cells}

To prove the therapeutic effect of anti-ENO1 mAb, SCID-beige mice were injected i.v. with luciferaseexpressing CFPAC-1 cells, and treated biweekly until sacrifice with anti-ENO1 mAb or isotype-matched control $\mathrm{mAb}$. Notably, CFPAC-1 cells resulted in large masses at the lymph node level, prior to lung tumors. Anti-ENO1 $\mathrm{mAb}$ treatment led to a reduced number of tumor masses compared to control treatment. This effect was most evident from day 14 onwards, and the difference between anti-ENO1 mAb-treated mice and control mice was even greater on day 28 (Fig. 5a left). Post-mortem observations confirmed a reduced number of tumor masses in antiENO1 mAb-treated mice compared to control mice (Fig. 5a right). Only a few mice developed lung metastasis (4 out of 15 mice), confirmed by hematoxylin-eosin stained lung sections (data not shown). This number of mice was too small to appreciate significant differences in the number and size of lung metastasis between treated and control groups.

An additional experiment was performed using NSG
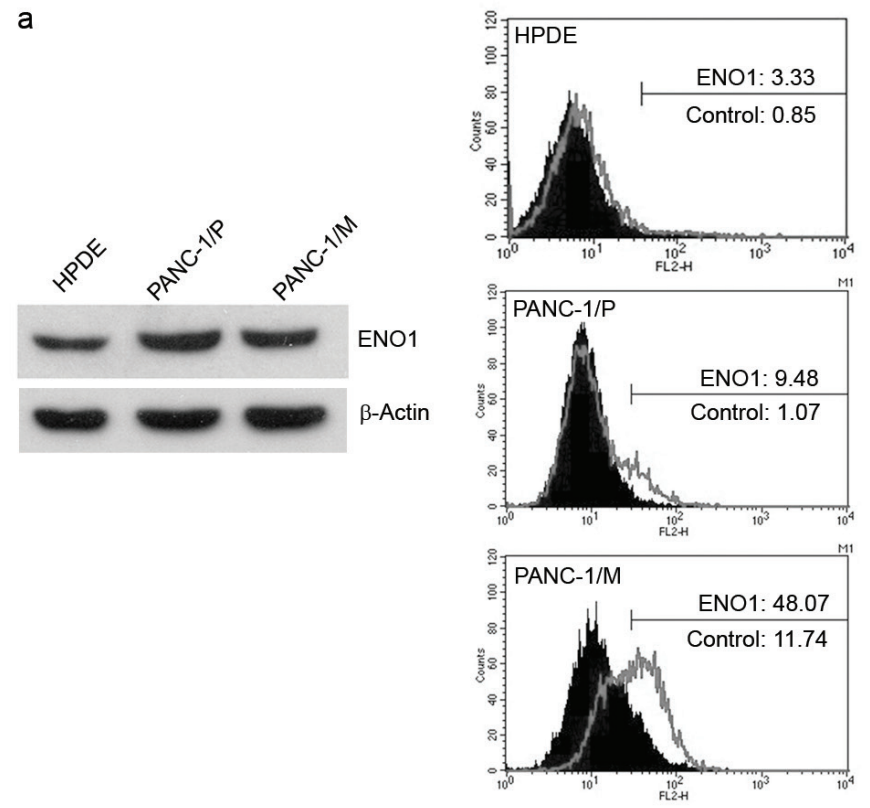

mice. Mice were pre-treated for 3 days with anti-ENO1 or control Abs prior to tumor challenge. At day 0, NSG mice were injected i.v. with luciferase-expressing CFPAC-1 cells, and treated biweekly with the mAbs until sacrifice. As early as day 14 after tumor injection, anti-ENO1 mAbtreated mice emitted a significantly reduced number of photons compared to the control group, as evaluated by IVIS spectrum technology (Fig. 5b).

\section{An AAVV strongly increases the anti-tumor role of anti-ENO1 mAb}

To further enhance the effect of anti-ENO1 mAb by continuous production of the antibody, NSG mice were injected with $1 \times 10^{11}$ genocopies of Adeno-Associated Viral (AAV) vector expressing anti-ENO1 72/1 mAb, or control AAV, into femoral muscle, 7 days prior to i.v. CFPAC-1 cell injection (Fig. 5c upper panel). At day -7, 7 and 28 , blood from mice was taken and analyzed for the presence of anti-ENO1 mAb. A progressively increasing concentration of anti-ENO1 mAb was observed, showing that AAVV facilitated a continuous, long-lasting and sustained production of circulating anti-ENO1 mAb (Fig. 5 c lower panel). On day 28, mice injected with AAVV expressing anti-ENO1 mAb showed a significant decrease in lung metastases compared to control mice (Fig. 5d).

\section{DISCUSSION}

Evidence from experimental models suggests that cell-associated plasminogen and its activators play a central role in tumor invasion [5, 14-16]. Numerous extracellular proteins have been identified as plasminogen

b
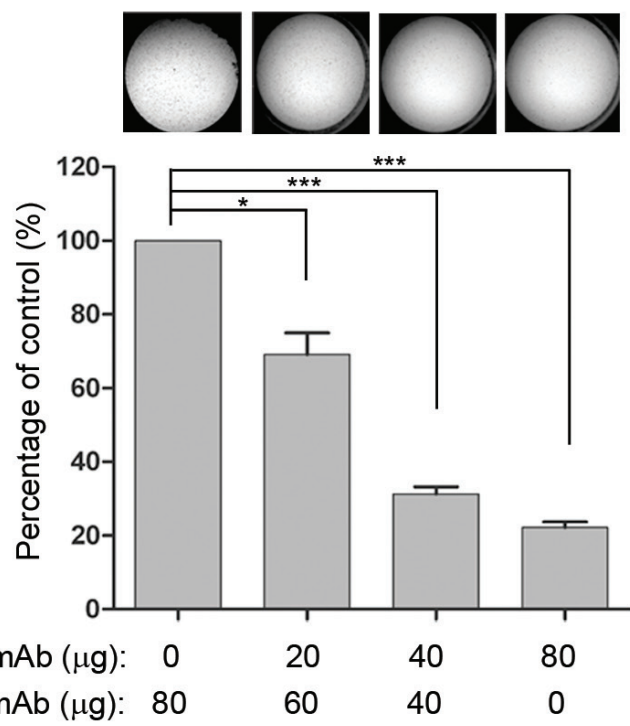
C
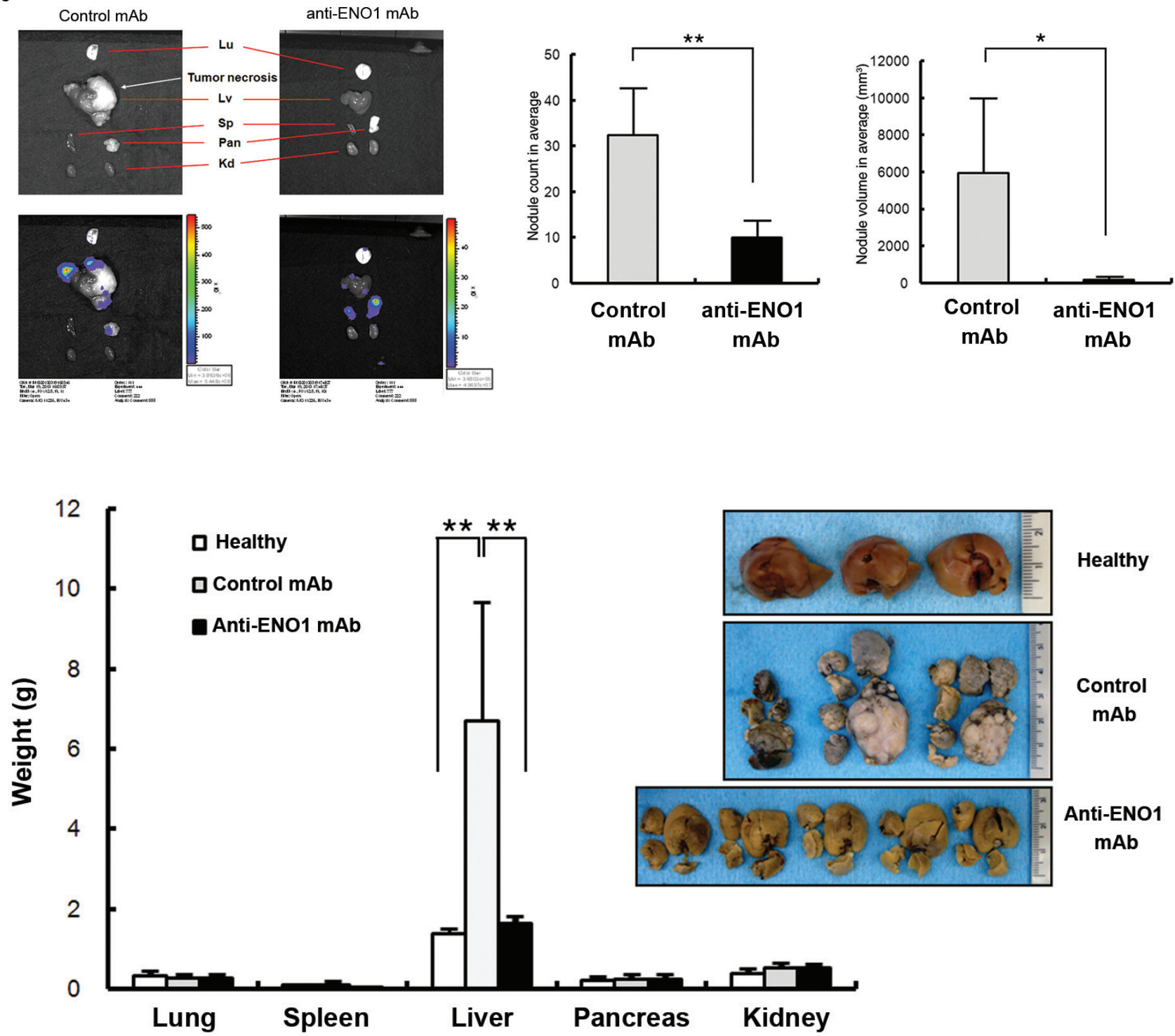

Figure 4: Capacity of the anti-ENO1 E10A mAb to inhibit in vitro and in vivo invasion of pancreatic cancer cells. (a) Left panel, Western blot analysis of total ENO1 expression in HPDE, PANC-1/P and PANC-1/M cells using an in-house purified rabbit antiserum against ENO1. $\beta$-Actin was used as a loading control. Right panel, flow-cytometric analysis of cell-surface ENO1 in HPDE, PANC-1/P and PANC-1/M cells using anti ENO1 E10A (empty area) or its isotype-control Ab (black area). (b) Dose-dependent inhibition of cell invasion by the anti ENO1 E10A mAb in PANC-1/M cells. Cells that degraded tumor-associated matrix and migrated through the membrane were stained and quantified with the ImageJ image-processing software. One representative pair is shown in the upper panel. Data are expressed as means \pm SEM and are represented as a fold-decrease in the invasive ability of cells treated with different doses of the anti ENO1 E10A mAb, compared with that of cells treated with the control antibody (lower panel). (c) Blockade of liver metastasis by the anti-ENO1 E10A mAb in an orthotopic pancreatic tumor model. Intravenous administration of the anti-ENO1 E10A ( $250 \mu \mathrm{g} / \mathrm{mouse})$ or control mAbs was performed at $2 \mathrm{~h}$ and $24 \mathrm{~h}$ after tumor inoculation. The tissue distribution of the luciferase-expressing cells was monitored using the IVIS image system every 2 weeks for a total of 6 weeks. Mice were sacrificed after 6 weeks. Organs from one pair of representative mice treated with the anti-ENO1 or control mAbs, as indicated, were photographed (upper left). Metastatic tumors in different organs were visualized by exposure for 10s and 1s, respectively, in the luminescent mode of the IVIS system. Upper right; after mice were sacrificed, the number and volume of metastatic tumor nodules in livers of mice treated with the anti- ENO1 (black) or control (gray) $\mathrm{mAbs}$ were quantified. Data are expressed as the mean $\pm \mathrm{SEM}$ of each group of mice. Lower panel, intact individual organs obtained from mice treated with the anti-ENO1 (black) or control (gray) mAbs were weighed, as indicated at the bottom. Quantitative data from each treatment are presented in the histograms. Normal livers taken from age-matched, untreated mice (white) served as healthy controls; * and ** indicate $P<0.05$ and $P<0.01$, respectively. For the in vivo experiment, five mice per group were used. 
receptors, including ENO1, ANX2 and CK8 [9], which are often de-regulated in cancer.

In this study, we identified ENO1 on the surface of human PDAC cells. Notably, among the eight cell lines tested, ENO1 was expressed at intermediate or high levels in metastatic cell lines (Hs766T[17], T3M4[18], CFPAC-1[19], L3.6pl[20]), and was absent or expressed at lower levels in primary tumor-derived cell lines
(BxPC3[21], PANC-1[22], PT45[23], Mia-PaCa2[24]). Ex vivo analysis of PANC-1 cells from a liver metastasis showed that the surface expression of ENO1 was higher compared to the parental cells from the primary tumor. This suggests that spreading and invasion of PDAC cells is strictly related to the high cell surface expression of ENO1, which, in turn, facilitates binding of elevated concentrations of plasminogen at the cell surface.

a
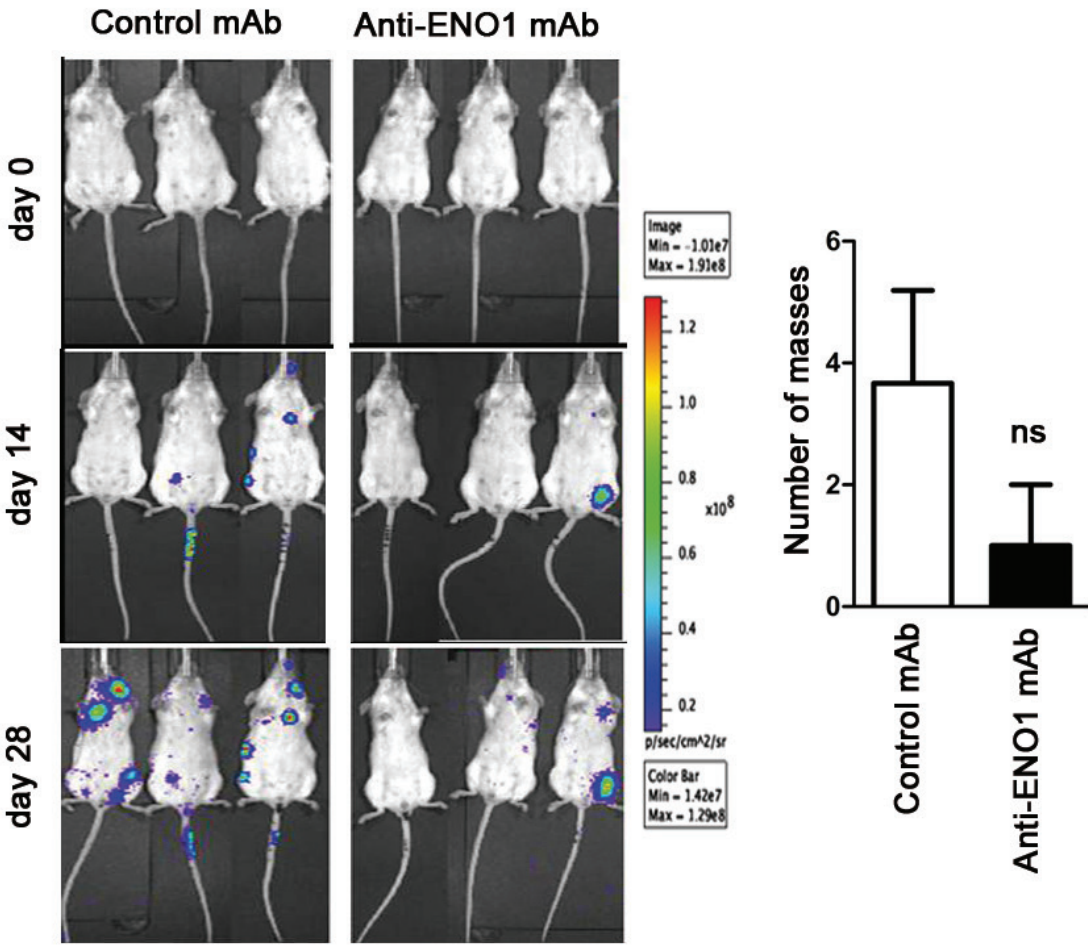

b

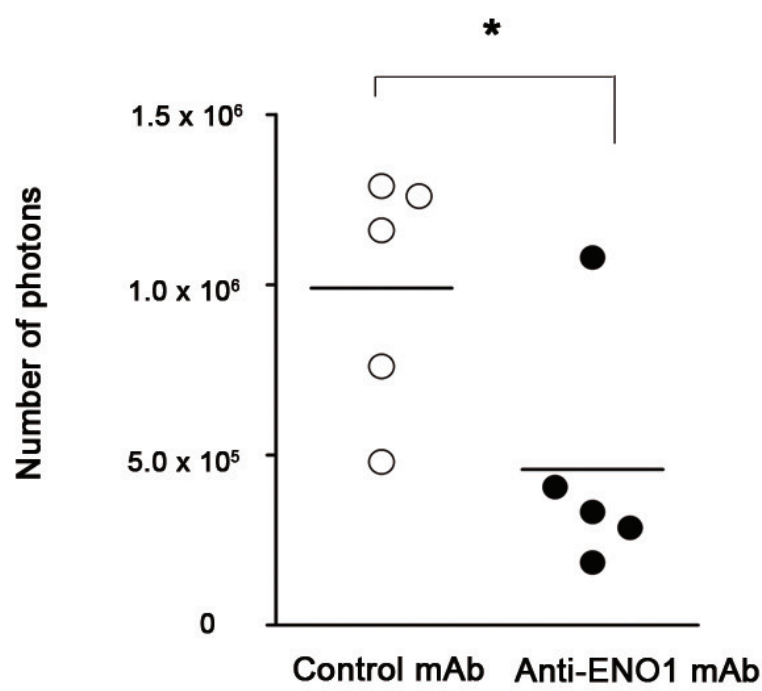



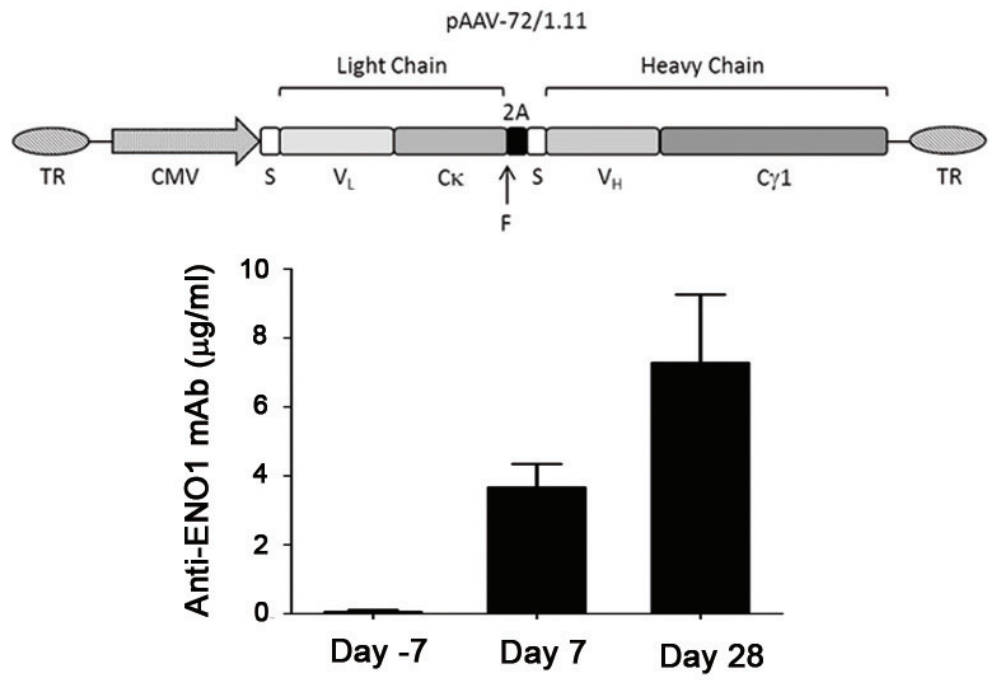

d
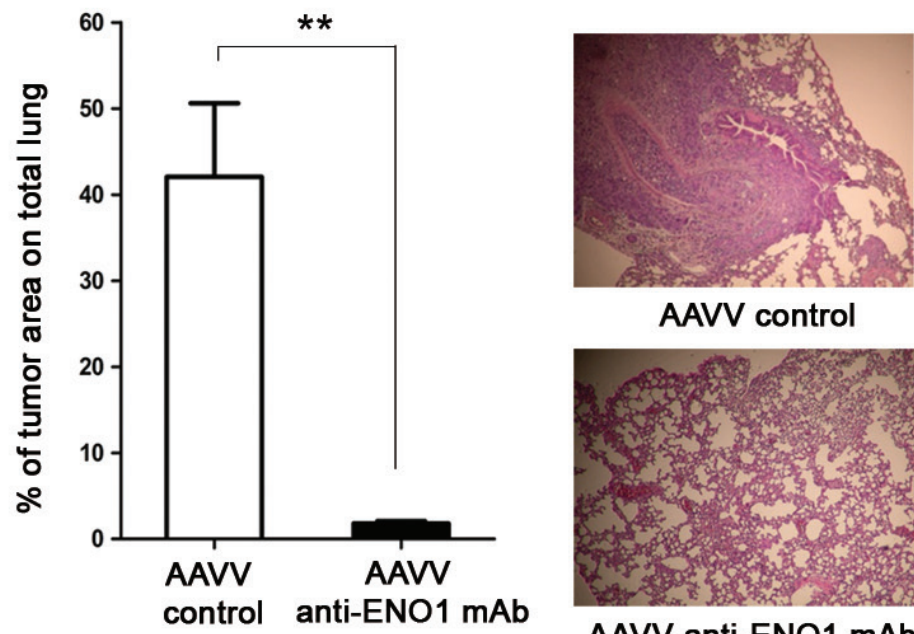

AAVV control

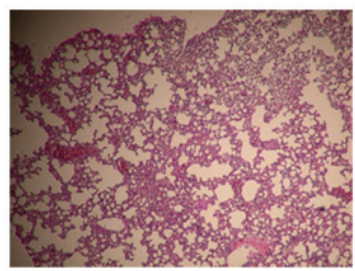

AAVV anti-ENO1 mAb

Figure 5: Effect of multiple injection or single injection of AAVV-anti-ENO1 72/1 mAb in the pancreatic mouse model. Effect of biweekly i.p. injections of anti-ENO1 72/1 mAb or an IgG1 isotype-matched control mAb (500 $\mu$ g per mouse) in SCID-beige (a) or NSG (b) mice injected i.v. with luciferase-expressing CFPAC-1 cells were monitored by in vivo imaging. Image shows three representative mice for each treatment group followed during the experiment (day 0, day 14 and day 28). Graph shows the mean \pm SEM number of tumor masses from each out of five mice. (b) From day 0 to day 14, tumor growth was monitored with IVIS spectrum technology. Results are expressed as absolute number of emitted photons at day 14. (c) Upper panel, schematic representation of the recombinant AAV vector expressing the anti-enolase 72/1.11 IgG1. TR: AAV terminal repeats sequences; CMV: cytomegalovirus promoter; S: secretion signal; $\mathrm{V}_{\mathrm{L}}$ : $\mathrm{mAb} 72 / 1.11 \mathrm{~V}_{\mathrm{L}}$ region; $\mathrm{C} \kappa$ : mouse $\kappa$ constant region; F: furin cleavage site; $2 \mathrm{~A}$ : FMDV peptide $2 \mathrm{~A}$ sequence; $\mathrm{V}_{\mathrm{H}}: \mathrm{mAb}^{2} / 1.11 \mathrm{~V}_{\mathrm{H}}$ region; $\mathrm{C} \gamma 1$ : mouse $\gamma 1$ constant region. Lower panel, evaluation of anti-ENO1 mAb concentration in sera from NSG mice intramuscularly injected with AAVV-anti-ENO1 72/1 mAb and after 7 days i.v. with CFPAC-1 by ELISA. (d) On day 28 after tumor challenge, mice were sacrificed and lung metastases were stained with hematoxylin-eosin and counted. Bars represent the percentage of tumor area calculated as follows: (tumor area / total area) x 100. Representative images of lung sections from control and treated mice are shown. For the in vivo experiment, five mice per group were used. $* \mathrm{p}<0.05 ; * * \mathrm{p}<0.01 ; * * \mathrm{p}<0.001$ 
Plasminogen expressed at the cell surface activates plasmin, increasing the ability of PDAC cells to degrade the ECM. However, the mechanism by which ENO1 is expressed at the cell surface is still unknown. Hypoxia, a condition that characterizes tumor growth in vivo, upregulates ENO1 expression [25-27]; therefore, we cannot rule out that the surface expression of ENO1 results from a general increase of ENO1 transcription and translation. However, as ENO1 is phosphorylated, methylated and acetylated $[26,28]$ in PDAC cells, the role of these posttranslational modifications in the regulation of surface localization of ENO1 in PDAC cells should also be considered.

In this study, we demonstrated that the in vitro and in vivo blockade of ENO1 by treatment with two different specific $\mathrm{mAbs}$ reduced the migration and invasion capacity of PDAC cells. Indeed, the transduction of wild type ENO1, but not ENO1 carrying the mutated plasminogenbinding site, restored the plasminogen-dependent invasion of CFPAC-1 cells that had been previously suppressed due to ENO1 silencing. Taken together, these data strongly support the notion that ENO1 is involved in plasminogendependent invasion of PDAC.

In vitro, CFPAC-1 cells displayed an invasive ability in the presence of plasminogen, which could be ascribed to the endogenous expression of UPA and UPAR, as well as ENO1. Moreover, after exposure to TGF- $\beta$ ENO1-expressing T3M4 and L3.6pl cells were induced to up-regulate UPA and UPAR and to invade in response to plasminogen (Table S1). As the invasion of all these cell lines was inhibited by anti-ENO1 mAb this implies that ENO1 regulated the PDAC metastatic process in vivo where the TGF- $\beta$ is provided [12, 29-33]. Metastatic PANC-1/M cells derived from a liver metastasis, following orthotopical injection of PANC-1 cells in the pancreas, expressed higher levels of surface ENO1 compared to the primary tumor cells, suggesting a role for surface ENO1 in facilitating tumor spreading.

In vivo, blockade of ENO1 by two specific antiENO1 mAbs reduced tumor spreading in different mouse xenograft tumor models. In the SCID-beige tumor model, we observed a particular pattern of tumor dissemination, as cells grew in lymph-nodes without forming organ metastasis. Since PDAC cells express CXCR4, they can migrate towards the gradient of CXCL12 released by lymphoid organs and localize in lymph nodes [34]. By contrast, NGS null mice injected with CFPAC-1 cells did not develop lymph-node masses, probably because they lack functional lymph-nodes, but displayed classical lung tumor spreading. In both cases, specific treatment with anti-ENO1 mAb was effective in inhibiting tumor growth. Finally, in NOD-SCID mice that were orthotopically injected with PANC-1/M cells, the anti-ENO1 mAb was effective in inhibiting the spreading of liver metastasis.

The innovative use of AAV technology to increase the efficacy of anti-ENO1 mAb treatment in mice is noteworthy, and results in dramatic inhibition of metastasis in the NSG model. AAVV is non-pathogenic and the recombinant vector retains none of the viral genes, making it a safer alternative to live bacterial strains. The lack of the Rep gene of the AAV vector also limits its integration potential, and the vast majority of AAV vectors are thought to remain episomal [35]. This strategy has many advantages, namely resistance to the effects of $\mathrm{pH}$; a localized or broad cellular tropism depending on the AAVV serotype; efficient gene transfer; persistence of gene expression, and low toxicity in vivo. Moreover, AAV-based therapeutic strategies have been tested in humans, and several clinical trials have been shown to be successful in terms of initial safety and proof of concept [36].

Increased expression of ENO1 has been observed in many tumors $[9,26,37,38]$, together with its ability to induce an immune response both in vitro and in vivo $[10,39-42]$. Recently, we have demonstrated that ENO1 is expressed on the surface of lung tumor cells and promotes ECM degradation and invasion through a plasminogendependent process [16]. Our findings strongly suggest that surface ENO1 is involved in the invasion of PDAC cells, and that blockade of the ENO1/plasminogen interaction, by using an AAVV-ENO1 mAb, could provide a new therapeutic approach for the treatment of metastatic PDAC patients.

\section{MATERIALS AND METHODS}

\section{Cell Culture}

Human PDAC cell lines used: CFPAC-1, MIA PaCa2, BxPC-3 (all from ECACC), T3M4, PANC-1, Hs766T, L3.6pl and PT45 (all kindly provided by Prof. Paola Nisticò, Regina Elena National Cancer Institute, Rome, Italy). Cell lines were cultured in DMEM (Lonza, Milan, Italy) supplemented with 10\% FBS (Lonza), L-Glutamine (GE Healthcare, Milan, Italy) and $50 \mu \mathrm{g} / \mathrm{ml}$ of gentamicin (Gentalyn 40mg/ml, Essex Italia, Segrate, MI, Italy) at $37^{\circ} \mathrm{C}$ in a $5 \% \mathrm{CO}_{2}$ atmosphere. Cells were detached using a solution of PBS containing $0.25 \%$ TrypsinEDTA. HPDE cells were cultured in Keratinocyte-SFM medium (Invitrogen, Carlsbad, CA) supplemented with pituitary extract and recombinant EGF. PANC-1/P cells were generated by transduction of PANC-1 cells with dual reporter lentiviral particles (GeneCopoeia, Rockville, MD) to co-express GFP and firefly luciferase (Luc), followed by selection of stable transfectants using BD FACSJazz (BD Biosciences, San Jose, CA). PANC-1/M cells were obtained from metastatic liver tumors developed in an orthotopic pancreatic mouse model using PANC-1/P cells. 


\section{Flow cytometric analysis}

Cells $\left(1 \times 10^{5}\right)$ were incubated with a primary $\mathrm{mAb}$ or an isotype-matched negative control antibody for 20 $\min$ at $4^{\circ} \mathrm{C}$. The following primary Abs were used: mouse anti-human ENO1 72/1 IgG1 mAb $(10 \mu \mathrm{g} / \mathrm{ml})$ [43] and rabbit anti-human uPAR polyclonal antibody $(10 \mu \mathrm{g} / \mathrm{ml}$; Santa Cruz Biotechnology by D.B.A. Italia, Segrate, MI, Italy). An irrelevant murine IgG1 was used as a negative control (Dako, Milan, Italy). Cells were then incubated, accordingly, with a secondary biotinylated rabbit polyclonal anti-mouse $\mathrm{F}(\mathrm{ab}) 2 \mathrm{Ig}$ antibody $\left(20 \mathrm{~min}\right.$ at $\left.4^{\circ} \mathrm{C}\right)$ followed by phycoerythrin (PE)-conjugated streptavidin (SAPE), or Alexa Fluor 488 Goat anti-Rabbit IgG $(\mathrm{H}+\mathrm{L})$ antibody (LifeTechnologies, Monza, MB, Italy), for 20 $\min$ at $4{ }^{\circ} \mathrm{C}$. For detection of uPA, cells were fixed with $4 \%$ paraformaldehyde (20 min at room temperature (RT) and then permeabilized with 5\% saponin. Cells were incubated with a mouse anti-human uPA mAb $(0.5 \mu \mathrm{g} / \mathrm{ml}$; abcam by Prodotti Gianni, Milan, Italy). An irrelevant murine IgG1 was used as a negative control (Dako). Cells were then incubated with a secondary PE goat anti-mouse IgG antibody (BioLegend by Campoverde, Milan, Italy) for $20 \mathrm{~min}$ at $4^{\circ} \mathrm{C}$. Following this, cells were re-suspended in Dulbecco's Phosphate-Buffered Saline (DPBS), acquired with a FACSCalibur and analyzed using the CellQuest program (BD Bioscience, Buccinasco, MI, Italy). PANC$1 / \mathrm{P}, \mathrm{PANC}-1 / \mathrm{M}$ and HPDE cells were stained with the mouse anti-human ENO1 E10A IgG2a mAb or its isotype control $(1.5 \mu \mathrm{g} / \mathrm{mL})$ for $30 \mathrm{~min}$ on ice, visualized with goat anti-mouse $\mathrm{F}\left(\mathrm{ab}^{\prime}\right)_{2}$ conjugated $\mathrm{PE}(2.5 \mu \mathrm{g} / \mathrm{mL}$; Jackson ImmunoResearch, Cambridgeshire, UK), and analyzed using the FACScan flow cytometer (BD Biosciences).

\section{Western blot analysis}

PDAC cells $\left(1 \times 10^{7}\right)$ from the various cell lines were harvested, lysed, resolved and transferred to nitrocellulose membranes, as previously described [40]. Membranes were incubated for $1 \mathrm{~h}$ at RT with anti-ENO1 72/1 mAb or rabbit polyclonal anti- $\beta$-Actin antibody (Sigma-Aldrich), at dilutions of 1:2000 in Tween-Tris-Buffered Saline (TTBS) and then probed with a horseradish peroxide (HRP)-conjugated anti-mouse IgG (Santa Cruz) or HRP-conjugated goat anti-rabbit Ig secondary antibody (Sigma-Aldrich) at dilutions of 1:2000. For Western blot analysis of ENO1 in PANC-1/P, PANC-1/M and HPDE cells, membranes were probed with in-house purified rabbit antiserum against ENO1 or with mouse antibody specific to $\beta$-Actin (Sigma St. Louis, MO, USA) as a protein loading control. Immunocomplexes were detected by probing with appropriate secondary antibodies conjugated with HRP (Jackson ImmunoResearch), and were visualized using the SuperSignal detection system (Thermo Fisher, Waltham, MA, USA).

\section{In vitro chemo-invasion assay}

Porous ( $8 \mu \mathrm{m}$ pore size) tissue culture inserts $(6.5$ $\mathrm{mm}$ diameter) (Costar by Sigma-Aldrich) were coated with $50 \mu$ of Matrigel (BD Biosciences) diluted at 1:8 in serumfree DMEM, and incubated for $4 \mathrm{~h}$ at $37^{\circ} \mathrm{C}$. Inserts were placed in a 24-well plate containing $0.6 \mathrm{ml} /$ well of DMEM supplemented with $3 \%$ FBS. Cells $\left(1 \times 10^{5} /\right.$ well $)$ were seeded in triplicate in serum-free medium in the upper chamber and incubated for $48 \mathrm{~h}$ at $37^{\circ} \mathrm{C}$. Plasminogen Glu-Type $(1 \mu \mathrm{g} / \mathrm{ml}$ or $10 \mu \mathrm{g} / \mathrm{ml}$; Calbiochem by D.B.A.), anti-ENO1 72/1 mAb or IgG1 isotype-matched control antibody $(50 \mu \mathrm{g} / \mathrm{ml}$; anti-intracellular domain of the IFN$\gamma$ R2, $\gamma$ R37) [44], Epsilon-Amino-Caproic Acid (EACA) $(50 \mathrm{mM}$; Calbiochem) and TGF- $\beta(1 \mathrm{ng} / \mathrm{ml}$ or $10 \mathrm{ng} / \mathrm{ml}$; Peprotech by Tebu-bio, Magenta, MI, Italy) were added to appropriate inserts. After incubation, invasive cells were fixed in $2 \%$ glutaraldehyde, stained with Crystal Violet (Sigma-Aldrich), treated with a $10 \%$ acetic acid solution (Sigma-Aldrich), and eluates were read at $570 \mathrm{~nm}$ with a spectrophotometer (Bio-Rad laboratories, Segrate, MI, Italy). For analysis of the HPDE, PANC-1/P and PANC$1 / \mathrm{M}$ cell lines, $5 \times 10^{4}$ cells/well were seeded and incubated, as described above, with anti-ENO1 E10A or with control $\mathrm{mAb}$. After incubation for $24 \mathrm{~h}$, cells were fixed, stained with Gimsa, and quantified by the ImageJ analysis [45]. Invasion assays in the presence of plasminogen alone $(40 \mu \mathrm{g} / \mathrm{ml})$ or with anti-ENO1 $72 / 1 \mathrm{mAb}(50 \mu \mathrm{g} / \mathrm{ml})$ or with mouse IgG1 control $(50 \mu \mathrm{g} / \mathrm{ml})$ were also carried out with a Cell Migration Assembly Kit, Oris ${ }^{\mathrm{TM}}$ - FLEX (Platipus Technology by TEMA Ricerca, Bologna, Italy) according to the manufacturer's instructions.

\section{Silencing of ENO1 in the PDAC cell line CFPAC-1}

Two Mission short hairpin RNA (shRNA), one targeting the 3'UTR of the gene coding for ENO1 (TRCN0000029324) and one targeting the CDS region (TRCN0000029327) were used to transform bacteria (Sigma-Aldrich, Milan, Italy); plasmids were purified with the PureLink HiPure Plasmid Maxiprep Kit (LifeTechnologies). Lentiviruses were produced by co-transfecting 293T packaging cells (Clontech by Diatech Lab Line Srl, Jesi, AN, Italy) with pLKO.1 puro vector containing the shRNA and the helper vectors pCMV 88.74 (Add gene, Cambridge, MA, USA) and pVSV-G (Clontech), using the calcium phosphate method. Lentiviruses collected at $24 \mathrm{~h}$ after transfection were used for the transduction of the CFPAC-1 cell line supplemented with $8 \mu \mathrm{g} / \mathrm{ml}$ polybrene (Sigma-Aldrich) and, after $48 \mathrm{~h}$ of infection, cells were then selected for stable silencing using $2 \mu \mathrm{g} / \mathrm{ml}$ Puromycin (Sigma-Aldrich). For quantitative mRNA expression analysis, a polymerase chain reaction (PCR) was carried out with total cDNA and the SYBR Green PCR Master Mix (LifeTechnologies), 
with a two-step amplification protocol. mRNA expression of target genes was normalized using the mRNA level of $\beta$-Actin.

\section{Plasmid construction and mutagenesis}

The total RNA from CFPAC-1 cell lines was extracted using the RNeasy Mini kit (Qiagen, Milan, Italy). RNA concentration and purity was determined using a NanoDrop instrument (Thermo Scientific by VWR, Milan, MI, Italy), and $1 \mu \mathrm{g}$ of the total RNA was used as a template for cDNA synthesis using the iScript cDNA synthesis kit (BioRad, Segrate, MI, Italy). Using the specific primers (Table S2) encoding for ENO1, cDNA was amplified by PCR; amplification products were analyzed on 1\% agarose gels, and isolated from gels by using a Gel Extraction Kit (Qiagen), ligated with the EGFP retroviral vector Pallino-GFP [46], using the XhoI and NotI restriction sites, transformed into Top 10 competent cells (LifeTechnologies), and sequenced. A mutated form of ENO1, bearing mutations in its plasminogen binding sites on lysines, 420, 422 and 434 (substituted by arginines) was obtained by three different point mutations using primers containing K420R, K422R and K434R substitutions (Table S2) and the QuikChange site-directed mutagenesis kit (Stratagene by Eppendorf, Milan, Italy); real-time PCR was performed using the C 1000 thermal cycler (BioRad). The PCR product was subsequently subjected to sequencing.

\section{Establishment of the PDAC cell line CFPAC-1 expressing ENO1 and the ENO1 mutant variant}

The retrovirus was obtained by transfecting the Pallino-GFP vector containing the ENO1 gene or the ENO1 mutant variant (K420R, K422R and K434R) into the GP-293 packaging cells (Clontech) co-transfected with the pVSV-G helper vector (Clontech) using the calcium phosphate method. Released retroviruses were collected at $24 \mathrm{~h}$ after transfection, and used for transduction of the 3'UTR ENO1-silenced CFPAC-1 (shENO1) cell line in the presence of $8 \mu \mathrm{g} / \mathrm{ml}$ polybrene (Sigma-Aldrich). After $12 \mathrm{~h}$ of incubation, complete medium was added and cells were cultured for a further 2 days. Cells were then analyzed for GFP content on a FACS Calibur flow cytometer (BD Biosciences). The CELLQuest TM software (BD Biosciences) was used for data acquisition and analysis of the cells expressing the full-length exogenous ENO1 (shENO1+WT), the triple-mutated ENO1 (shENO1+TM), as well as cells expressing the empty vector (shENO1+Empty) as a control. Expression of protein levels was also analyzed by Western blotting.

\section{Enzyme-Linked Immunosorbent Assay (ELISA)}

The plasminogen-binding assay was performed with a recombinant human ENO1 (rENO1) protein histidine-tag (rENO1 WT) or a mutated form (rENO1 TM), produced as previously described [10]. Briefly, rENO1 $(2.5 \mu \mathrm{g} / \mathrm{mL}$ in $0.1 \mathrm{M} \mathrm{Na}_{2} \mathrm{CO}_{3}$ ) was coated in 96-plate well and incubated over-night at $4{ }^{\circ} \mathrm{C}$. After $2 \mathrm{~h}$ of blocking with PBS 3\% bovine serum albumin (BSA) at RT, plasminogen diluted in PBS $1 \%$ BSA $0.05 \%$ Tween was added at different doses for $1 \mathrm{~h}$ at RT. After incubation with StreptavidinHRP (Sigma) and then with tetramethylbenzidine (TMB) (Sigma), the plate was read at the spectrophotometer at a wavelength of $450 \mathrm{~nm}$.

Anti-ENO1 mAb levels were measured by ELISA, by binding to $\mathrm{rENO} 1\left(2 \mu \mathrm{g} / \mathrm{mL}\right.$ in $\left.0.1 \mathrm{M} \mathrm{Na}_{2} \mathrm{CO}_{3}\right)$. Sera collected before the injection of AAVV and 2 and 5 weeks after the injection were diluted at 1:100 in DPBS, and antibody concentrations were calculated by regression analysis using seven 2-fold serial dilutions starting from $1 \mu \mathrm{g} / \mathrm{mL}$ of anti-ENO1 $72 / 1 \mathrm{mAb}$ for creating a standard curve [39].

\section{Construction of the recombinant adeno-associated viral vector $(\mathrm{AAVV})$ for the expression of complete anti-ENO1 72/1 mAb}

Total RNA was extracted from hybridoma 72/1 cells [43] using the RNeasy Mini Kit (Qiagen), and $\mathrm{V}_{\mathrm{L}}$ and $\mathrm{V}_{\mathrm{H}}$ genes were amplified by RT-PCR with primer pairs LB13 (GAYATTGTGATGACYCAGKC) / Ск2 (TGGATACAGTTGGTGCAGC) and VHB (AGGTSMARCTGCAGSAGTCWGG) / $\mathrm{CH} \gamma$ (GGCCAGTGGATAGAC), respectively. Amplified fragments were sequenced and reamplified with primer pairs VL12-BssHII (ATAGCGCGCCGTTTCAGCTCCAGCTTGGT) / VL12EcoRV (ACTCGGATATCGTGATGACCCAGGCT) for $\quad V_{L}$ and VH14-ApaLI (TATAGTGCACTCTCAGGCCTATCTGCAGCAGT)/ VH14-Eag/BspE(TAATTCCGGACGGCCGAAGAGAC AGTGACCAGAGT) for $\mathrm{V}_{\mathrm{H}}$, to allow the reconstitution of complete functional light- and heavy-chain genes for the anti-ENO1 mAb. Re-amplified V genes were inserted into a vector derived from pcDNA3 (Life Technologies) containing the sequences of the constant regions of the mouse $\kappa$ light chain and $\gamma 1$ heavy chain arranged in a single transcriptional unit, where the light chain and heavy chain genes are separated by a sequence encoding the autocatalytic peptide 2A from the FMD Virus; the two genes contained in this bicistronic mRNA are translated into a single polypeptide that spontaneously cleaves into two distinct proteins [47]. To remove the residual peptide $2 \mathrm{~A}$, a sequence encoding a furin cleavage site (RSKR) was introduced between the light-chain and the peptide 
2A coding sequences [48]. The $\mathrm{V}_{\mathrm{L}}$ sequence was inserted into BssHII/EcoRV in this bicistronic vector, in order to join it to the $\kappa$ constant region gene, while the $\mathrm{V}_{\mathrm{H}}$ segment was firstly inserted into ApaLI/BspEI in a pUT-SEC vector [49], in order to provide it with a sequence encoding a secretion signal; the SEC- $\mathrm{V}_{\mathrm{H}}$ unit was then excised with HindIII/EagI, and joined to the mouse $\gamma 1$ constant region gene in the bicistronic vector, downstream of the light chain gene and the $2 \mathrm{~A}$ sequence. The complete antiENO1 $\mathrm{mAb}$ transcriptional unit was then transferred to HindIII/XbaI in a plasmid vector, under the control of the cytomegalovirus immediate early promoter, to yield the final vector $\mathrm{pAAV}-72 / 1$. To confirm that this vector was able to direct the production of functional antibodies, 7 $\mu \mathrm{g}$ of pAAV-72/1 was used to transfect approximately $3 \times 10^{6}$ HEK293 cells using the standard calcium phosphate method, and supernatants were used to probe cellular extracts from PDAC cells by Western blotting. The reactivity of the secreted recombinant $\mathrm{mAb}$ was compared to that of the original 72/1 mAb (Fig. S4). The pAAV-72/1 vector was then used for the generation of recombinant AAV (serotype9) in the AVU (AAV Vector Unit) Core Facility of the ICGEB (Trieste, Italy), as described [50].

\section{In vivo experiments}

NOD-SCID IL2Rgamman ${ }^{\text {null }}$ (NSG) mice (provided by the animal facility of the Molecular Biotechnology Center, University of Turin, Italy) were injected in the tail vein (i.v.) with $1 \times 10^{5}$ CFPAC-1 shCTRL or shENO1+Empty, shENO1+WT, shENO1+TM cells (in $0.1 \mathrm{ml}$ DPBS) and the mice were euthanized after 28 days.

SCID-beige mice (Charles River, Calco, LC, Italy) or NSG mice were injected in the tail vein (i.v.) with $1 \times 10^{5}$ CFPAC- 1 cells expressing luciferase (in $0.1 \mathrm{ml}$ DPBS), followed by biweekly injections of anti-ENO1 $72 / 1 \mathrm{mAb}(500 \mu \mathrm{g} / \mathrm{mouse})$ or an isotype-matched control antibody. NSG mice were pre-treated for 3 days with the same antibodies. In a different set of experiments, NSG mice were injected 7 days before the i.v. CFPAC-1 cell challenge with $1 \times 10^{11}$ genocopies of AAVV expressing anti-ENO1 72/1 mAb or control AAVV in femoral muscles. For detection of in vivo growth of CFPAC-1 luciferase-transduced tumor cells, mice were anesthetized with $2 \%$ isofluorane and given i.p. injections of luciferin substrate (100 mg/kg) (Caliper Life Sciences by Promega, Milan, Italy), $10 \mathrm{~min}$ prior to imaging using the IVIS Spectrum in vivo Imaging System (Xenogen Corp., Alameda, CA, USA). Images were taken on day 0,14 and 28 after CFPAC-1 injection (SCID-beige mice) and on day 0 and 14 (NSG mice). Images were analyzed using Living Image software for the IVIS Spectrum (Xenogen Corp.). After 28 days, mice were euthanized and checked for metastasis by histological analysis.

For orthotopic experiments, NOD-SCID male mice (6-8 weeks old) were obtained from the National
Laboratory Animal Center, Taiwan, and housed under specific pathogen-free conditions according to the guidelines of the Animal Care Committee at the National Health Research Institutes, Taiwan. On Day 0, PANC-1/M cells expressing luciferase $\left(1 \times 10^{6} / 200 \mathrm{ml}\right.$ per mouse $)$ were orthotopically injected into the pancreases of the mice. The mice were intravenously administered with the antiENO1 E10A mAb (250 $\mu \mathrm{g} / \mathrm{mouse})$ or its isotype control, as indicated, at $2 \mathrm{~h}$ and $24 \mathrm{~h}$ after tumor inoculation. Tissue distribution of the cells was monitored using the IVIS in vivo imaging system every 2 weeks for a total of 6 weeks, as described above. Tumor volumes of metastatic tumors were measured using the following formula: length $(\mathrm{mm}) \times$ width $^{2}\left(\mathrm{~mm}^{2}\right) \times(\pi / 6)$. All organs from the mice treated with the anti-ENO1 E10A or control mAb, as well as of age-matched healthy mice were also weighed. In all experiments, five mice were used in each group.

\section{Tissue sample and histopathology}

Mice were euthanized, necropsied and examined for the presence of tumor masses. Tumor masses and main organs, including lungs, spleens, and livers were fixed in $4 \%(\mathrm{v} / \mathrm{v})$ neutral-buffered formalin (SigmaAldrich) overnight, transferred to $70 \%$ ethanol, followed by paraffin-embedding. For histological analysis, $5 \mu \mathrm{m}$ formalin-fixed paraffin-embedded tissue sections were cut and stained with hematoxylin-eosin. Tumor/normal tissue ratios were evaluated with ImageJ software.

\section{Statistical Analysis}

The Student's t test (GraphPad Prism 5 Software, San Diego, CA) was used to evaluate the differences in the invasion test, and in in vivo experiments. Values were expressed as mean $\pm \mathrm{SEM}$.

\section{ACKNOWLEDGMENTS}

We would like to thank Marina Dapas for the preparation of the AAVV used in this study, Roberta Curto for technical support in the in vivo experiments and Dr. Radhika Srinivasan and Dr. Marianne Murphy for critically reading the manuscript.

\section{FINANCIAL SUPPORT}

This work was supported in part by grants from the European Community, Seventh Framework Program (EPC-TM-Net, nr. 256974); Associazione Italiana Ricerca sul Cancro (5 x mille no. 12182) and (IG no. 15257); Regione Piemonte: Ricerca Industriale e Sviluppo Precompetitivo (ONCOPROT), Ricerca Industriale "Converging Technologies" (BIOTHER); Ministero dell'Istruzione e della Ricerca (MIUR), 
Progetti di Rilevante Interesse Nazionale (PRIN 2009); University of Turin-Progetti di Ateneo 2011 (grant RetheORTO11RKTW), Fondazione Ricerca Molinette. MP and MSC are supported by NatiMab Therapeutics.

\section{CONFLICTS OF INTEREST}

The authors declare no conflicts of interest.

\section{Authors' Contributions}

M.P. and P.Ce. designed and performed experiments, analyzed data and wrote the manuscript; N-Y.S developed and characterized the anti-ENO1 mAb, designed experiments, analyzed data and wrote the manuscript; S-H.Y., M.S.C., S.R. and L.C. performed experiments and analyzed data; P.M. developed and characterized the anti-ENO1 72/1 $\mathrm{mAb}$ and designed experiments; M.B., L.Z. and O.B. developed and characterized AAV-expressing $\mathrm{mAb}$ and analyzed data; P.Ca. performed experiments, analyzed data and revised the manuscript; F.N. supervised the study, analyzed data and wrote the manuscript.

\section{REFERENCES}

1. Siegel R, Naishadham D and Jemal A. Cancer statistics, 2013. CA Cancer J Clin. 2013; 63(1):11-30.

2. Michl P and Gress TM. Current concepts and novel targets in advanced pancreatic cancer. Gut. 2013; 62(2):317-326.

3. Dunphy EP. Pancreatic cancer: a review and update. Clin J Oncol Nurs. 2008; 12(5):735-741.

4. Maitra A and Hruban RH. Pancreatic cancer. Annu Rev Pathol. 2008; 3:157-188.

5. Andreasen PA, Egelund $\mathrm{R}$ and Petersen HH. The plasminogen activation system in tumor growth, invasion, and metastasis. Cell Mol Life Sci. 2000; 57(1):25-40.

6. Kwaan HC and McMahon B. The role of plasminogenplasmin system in cancer. Cancer Treat Res. 2009; 148:4366.

7. McMahon B and Kwaan HC. The plasminogen activator system and cancer. Pathophysiol Haemost Thromb. 2008; 36(3-4):184-194.

8. Blasi F and Sidenius N. The urokinase receptor: focused cell surface proteolysis, cell adhesion and signaling. FEBS Lett. 2010; 584(9):1923-1930.

9. Ceruti P, Principe M, Capello M, Cappello P and Novelli F. Three are better than one: plasminogen receptors as cancer theranostic targets. Exp Hematol Oncol. 2013; 2(1):12.

10. Cappello P, Tomaino B, Chiarle R, Ceruti P, Novarino A, Castagnoli C, Migliorini P, Perconti G, Giallongo A, Milella M, Monsurro V, Barbi S, Scarpa A et al. An integrated humoral and cellular response is elicited in pancreatic cancer by alpha-enolase, a novel pancreatic ductal adenocarcinoma-associated antigen. Int $\mathrm{J}$ Cancer. 2009; 125(3):639-648.

11. Amedei A, Niccolai E, Benagiano M, Della Bella C, Cianchi F, Bechi P, Taddei A, Bencini L, Farsi M, Cappello P, Prisco D, Novelli F and D'Elios MM. Ex vivo analysis of pancreatic cancer-infiltrating $\mathrm{T}$ lymphocytes reveals that ENO-specific Tregs accumulate in tumor tissue and inhibit Th1/Th17 effector cell functions. Cancer Immunol Immunother. 2013; 62(7):1249-1260.

12. Albo D, Berger DH and Tuszynski GP. The effect of thrombospondin-1 and TGF-beta 1 on pancreatic cancer cell invasion. J Surg Res. 1998; 76(1):86-90.

13. Miles LA, Dahlberg CM, Plescia J, Felez J, Kato K and Plow EF. Role of cell-surface lysines in plasminogen binding to cells: identification of alpha-enolase as a candidate plasminogen receptor. Biochemistry. 1991; 30(6):1682-1691.

14. Keleg S, Buchler P, Ludwig R, Buchler MW and Friess H. Invasion and metastasis in pancreatic cancer. Mol Cancer. $2003 ; 2: 14$.

15. Tan X, Egami H, Nozawa F, Abe M and Baba H. Analysis of the invasion-metastasis mechanism in pancreatic cancer: involvement of plasmin(ogen) cascade proteins in the invasion of pancreatic cancer cells. Int J Oncol. 2006; 28(2):369-374.

16. Hsiao KC, Shih NY, Fang HL, Huang TS, Kuo CC, Chu PY, Hung YM, Chou SW, Yang YY, Chang GC and Liu KJ. Surface alpha-enolase promotes extracellular matrix degradation and tumor metastasis and represents a new therapeutic target. PLoS One. 2013; 8(7):e69354.

17. Owens RB, Smith HS, Nelson-Rees WA and Springer EL. Epithelial cell cultures from normal and cancerous human tissues. J Natl Cancer Inst. 1976; 56(4):843-849.

18. Okabe T, Yamaguchi N and Ohsawa N. Establishment and characterization of a carcinoembryonic antigen (CEA)producing cell line from a human carcinoma of the exocrine pancreas. Cancer. 1983; 51(4):662-668.

19. Schoumacher RA, Ram J, Iannuzzi MC, Bradbury NA, Wallace RW, Hon CT, Kelly DR, Schmid SM, Gelder FB, Rado TA and et al. A cystic fibrosis pancreatic adenocarcinoma cell line. Proc Natl Acad Sci U S A. 1990; 87(10):4012-4016.

20. Bruns CJ, Harbison MT, Kuniyasu H, Eue I and Fidler IJ. In vivo selection and characterization of metastatic variants from human pancreatic adenocarcinoma by using orthotopic implantation in nude mice. Neoplasia. 1999; 1(1):50-62.

21. Tan MH, Nowak NJ, Loor R, Ochi H, Sandberg AA, Lopez C, Pickren JW, Berjian R, Douglass HO, Jr. and Chu TM. Characterization of a new primary human pancreatic tumor line. Cancer Invest. 1986; 4(1):15-23.

22. Lieber M, Mazzetta J, Nelson-Rees W, Kaplan M and Todaro G. Establishment of a continuous tumor-cell line (panc-1) from a human carcinoma of the exocrine pancreas. Int J Cancer. 1975; 15(5):741-747. 
23. Kalthoff H, Schmiegel W, Roeder C, Kasche D, Schmidt A, Lauer G, Thiele HG, Honold G, Pantel K, Riethmuller G and et al. p53 and K-RAS alterations in pancreatic epithelial cell lesions. Oncogene. 1993; 8(2):289-298.

24. Yunis AA, Arimura GK and Russin DJ. Human pancreatic carcinoma (MIA PaCa-2) in continuous culture: sensitivity to asparaginase. Int J Cancer. 1977; 19(1):128-135.

25. Sedoris KC, Thomas SD and Miller DM. Hypoxia induces differential translation of enolase/MBP-1. BMC Cancer. 2010; 10:157.

26. Capello M, Ferri-Borgogno S, Cappello P and Novelli F. alpha-Enolase: a promising therapeutic and diagnostic tumor target. FEBS J. 2011; 278(7):1064-1074.

27. Semenza GL, Jiang BH, Leung SW, Passantino R, Concordet JP, Maire $\mathrm{P}$ and Giallongo A. Hypoxia response elements in the aldolase A, enolase 1, and lactate dehydrogenase A gene promoters contain essential binding sites for hypoxia-inducible factor 1. J Biol Chem. 1996; 271(51):32529-32537.

28. Zhou W, Capello M, Fredolini C, Piemonti L, Liotta LA, Novelli $\mathrm{F}$ and Petricoin EF. Mass spectrometry analysis of the post-translational modifications of alpha-enolase from pancreatic ductal adenocarcinoma cells. J Proteome Res. 2010; 9(6):2929-2936.

29. Dano K, Behrendt N, Hoyer-Hansen G, Johnsen M, Lund LR, Ploug $\mathrm{M}$ and Romer J. Plasminogen activation and cancer. Thromb Haemost. 2005; 93(4):676-681.

30. Hildenbrand R, Schaaf A, Dorn-Beineke A, Allgayer H, Sutterlin M, Marx A and Stroebel P. Tumor stroma is the predominant uPA-, uPAR-, PAI-1-expressing tissue in human breast cancer: prognostic impact. Histol Histopathol. 2009; 24(7):869-877.

31. Ulisse S, Baldini E, Sorrenti S and D'Armiento M. The urokinase plasminogen activator system: a target for anticancer therapy. Curr Cancer Drug Targets. 2009; 9(1):3271.

32. Bauer TW, Liu W, Fan F, Camp ER, Yang A, Somcio RJ, Bucana CD, Callahan J, Parry GC, Evans DB, Boyd DD, Mazar AP and Ellis LM. Targeting of urokinase plasminogen activator receptor in human pancreatic carcinoma cells inhibits c-Met- and insulin-like growth factor-I receptor-mediated migration and invasion and orthotopic tumor growth in mice. Cancer Res. 2005; 65(17):7775-7781.

33. Lund LR, Ellis V, Ronne E, Pyke C and Dano K. Transcriptional and post-transcriptional regulation of the receptor for urokinase-type plasminogen activator by cytokines and tumour promoters in the human lung carcinoma cell line A549. Biochem J. 1995; 310 ( Pt 1):345352.

34. Sun X, Cheng G, Hao M, Zheng J, Zhou X, Zhang J, Taichman RS, Pienta KJ and Wang J. CXCL12 / CXCR4 / CXCR7 chemokine axis and cancer progression. Cancer Metastasis Rev. 2010; 29(4):709-722.
35. Flotte TR and Carter BJ. Adeno-associated virus vectors for gene therapy. Gene Ther. 1995; 2(6):357-362.

36. Aalbers CJ, Tak PP and Vervoordeldonk MJ. Advancements in adeno-associated viral gene therapy approaches: exploring a new horizon. F1000 Med Rep. 2011; 3:17.

37. Chang GC, Liu KJ, Hsieh CL, Hu TS, Charoenfuprasert S, Liu HK, Luh KT, Hsu LH, Wu CW, Ting CC, Chen CY, Chen KC, Yang TY et al. Identification of alpha-enolase as an autoantigen in lung cancer: its overexpression is associated with clinical outcomes. Clin Cancer Res. 2006; 12(19):5746-5754.

38. Dowling P, Meleady P, Dowd A, Henry M, Glynn S and Clynes M. Proteomic analysis of isolated membrane fractions from superinvasive cancer cells. Biochim Biophys Acta. 2007; 1774(1):93-101.

39. Cappello P, Rolla S, Chiarle R, Principe M, Cavallo F, Perconti G, Feo S, Giovarelli $\mathrm{M}$ and Novelli F. Vaccination With ENO1 DNA Prolongs Survival of Genetically Engineered Mice With Pancreatic Cancer. Gastroenterology. 2013; 144(5):1098-1106.

40. Tomaino B, Cappello P, Capello M, Fredolini C, Ponzetto A, Novarino A, Ciuffreda L, Bertetto O, De Angelis C, Gaia E, Salacone P, Milella M, Nistico P et al. Autoantibody signature in human ductal pancreatic adenocarcinoma. $\mathrm{J}$ Proteome Res. 2007; 6(10):4025-4031.

41. Tomaino B, Cappello P, Capello M, Fredolini C, Sperduti I, Migliorini P, Salacone P, Novarino A, Giacobino A, Ciuffreda L, Alessio M, Nistico P, Scarpa A et al. Circulating autoantibodies to phosphorylated alpha-enolase are a hallmark of pancreatic cancer. J Proteome Res. 2011; 10(1):105-112.

42. Saulot V, Vittecoq O, Charlionet R, Fardellone P, Lange C, Marvin L, Machour N, Le Loet X, Gilbert D and Tron F. Presence of autoantibodies to the glycolytic enzyme alphaenolase in sera from patients with early rheumatoid arthritis. Arthritis Rheum. 2002; 46(5):1196-1201.

43. Moscato S, Pratesi F, Sabbatini A, Chimenti D, Scavuzzo M, Passatino R, Bombardieri S, Giallongo A and Migliorini P. Surface expression of a glycolytic enzyme, alphaenolase, recognized by autoantibodies in connective tissue disorders. Eur J Immunol. 2000; 30(12):3575-3584.

44. Garotta G, Ozmen L, Fountoulakis M, Dembic Z, van Loon AP and Stuber D. Human interferon-gamma receptor. Mapping of epitopes recognized by neutralizing antibodies using native and recombinant receptor proteins. J Biol Chem. 1990; 265(12):6908-6915.

45. Ghislin S, Obino D, Middendorp S, Boggetto N, AlcaideLoridan C and Deshayes F. LFA-1 and ICAM-1 expression induced during melanoma-endothelial cell co-culture favors the transendothelial migration of melanoma cell lines in vitro. BMC Cancer. 2012; 12:455.

46. Grignani F, Kinsella T, Mencarelli A, Valtieri M, Riganelli D, Lanfrancone L, Peschle C, Nolan GP and Pelicci PG. High-efficiency gene transfer and selection of human 
hematopoietic progenitor cells with a hybrid EBV/retroviral vector expressing the green fluorescence protein. Cancer Res. 1998; 58(1):14-19.

47. de Felipe P, Martin V, Cortes ML, Ryan M and Izquierdo $\mathrm{M}$. Use of the $2 \mathrm{~A}$ sequence from foot-and-mouth disease virus in the generation of retroviral vectors for gene therapy. Gene Ther. 1999; 6(2):198-208.

48. Appleby SL, Irani Y, Mortimer LA, Brereton HM, Klebe $\mathrm{S}$, Keane MC, Cowan PJ and Williams KA. Co-expression of a scFv antibody fragment and a reporter protein using lentiviral shuttle plasmid containing a self-processing furin2A sequence. J Immunol Methods. 2013; 397(1-2):61-65.

49. Li E, Pedraza A, Bestagno M, Mancardi S, Sanchez R and Burrone O. Mammalian cell expression of dimeric small immune proteins (SIP). Protein Eng. 1997; 10(6):731-736.

50. Cesco-Gaspere M, Zentilin L, Giacca M and Burrone OR. Boosting anti-idiotype immune response with recombinant AAV enhances tumour protection induced by gene gun vaccination. Scand J Immunol. 2008; 68(1):58-66. 